The history of volcanic action in the past, and the conditions under which it is continued now in the polar regions; whether in high latitudes vulcanism, either in its internal magmas or superficial eruptions, manifests peculiarities not observable nearer to the equator; what is the nature of the volcanic products now ejected at the surface; whether a definite sequence can be established from the eruptions of still active volcanoes back into those of earlier geological periods in Antarctic lands; and whether among the older sheets leaf-beds or other intercalations may be traceable, indicating the prolongation of a welldeveloped terrestrial flora towards the south pole.

The influence of the Antarctic climate upon the rocks exposed to its action; the effects of contact with ice and snow upon streams of lava; the result of the seaward creep of the ice-cap in regard to any lava-sheets intercalated in the ice. It is conceivable that portions of lava-streams might be broken off by the onward motion of the ice which they overspread, and might thus be carried out to sea, intercalated in or capping ice-bergs-

The physics of Antarctic ice in regard to the history of the Ice Age in northern Europe and America.

\section{ANTARCTIC FAuna.}

Although an ardent advocate of Antarctic exploration, $\mathrm{Mr}$. Sclater acknowledged that, as regards the higher rertebrates, with which he was most conversant, there was little chance of the discovery of new forms of animal life in the South Polar continent. The Antarctic mammals and birds (of the latter of which about twenty species were known) were exclusively of marine forms. Not a single land-mammal or land-bird had been yet obtained in Antarctica. As regards the class of fishes and the marine invertebrates, the case was quite different, and great discoveries might be anticipated in these groups, where very little had yet been done. The most promising zoological subject of Antarctic exploration seemed to him, however, to be the further investigation of the extinct fauna. The few fossil remains already obtained indicated the former existence in the South Polar area of a very different climate from that which now prevailed there, and further researches on this point might lead to most important results.

Prof. D'Arcy W. Thompson said that all we knew of the deepsea life of the Antarctic came from eight hauls of the dredge, which hauls were, by common consent of the naturalists of the Challenger, the most productive of the whole cruise. The fauna of every ocean urgently demanded further exploration, for we knew now no more about the fauna of the deep-sea than was known a hundred years ago of the fauna of the shore. But the circumpolar fauna of the South, at the meeting of all the great oceans, presented problems of peculiar importance. $\mathrm{He}$ considered Dr. Murray's theory of a "bipolar fauna," closely akin both in the Arctic and Antarctic, as not proven; but he believed that there were many remarkable cases of continuous distribution, especially along the cold waters of the Western American coast from the Antarctic into the North Pacific, and even to Japan. If the "bipolar hypothesis" were broken down, Antarctic exploration would lead to new generalisations, not less interesting, to take its place.

Admiral Sir William Wharton said that an Antarctic Expedition must be under naval discipline. He hoped that such an expedition would not be far off, and he felt sure there would be a rush of officers and men to join it.

Sir John Evans, in briefly summing up the discussion, said it had maintained a high level, and that the meeting had been prolonged to an unprecedented hour in the Royal Society. All were agreed as to the immense advantages of an expedition, and he was sure it would find a warm advocate in the Hydrographer to the Admiralty.

\section{ON THE ABSORPTION OF LIGHT BY FLUORESCING BODIES. ${ }^{1}$}

$M R$. JOHN BURKE has recently given to the Royal $M$ Society of London (see NATURE, vol. Ivi. p. 26I) the result of somie experiments which afford an important indication of the mode of action of bodies during fluorescence, and which may lead to a clearer conception of Kirchhoff's law on the equality of the emissive and absorptive powers of bodies

The following is one form of Mr. Burke's experiment:-A

${ }_{1}^{1}$ Translation of a paper, by Prof. C. E. Guillaume, in the Revue Générale des Sciences, December 15, 1897.

NO. 1479, vOL. 57.] photographic plate, $\mathrm{P}$ (Fig. I), is adjusted before two equal cubes of uranium glass, $\mathrm{A}$ and $\mathrm{B}$, placed so that the light emanating from $\mathrm{B}$ is obliged to pass through $\mathrm{A}$ before reaching the photographic plate $P$.

The source of light, $\mathrm{s}$, rich in the ultra-violet, illuminates the cubes by rays parallel to the plate, which is screened from the direct action of the source. An image is first formed by letting the exciting rays act on the two cubes simultaneously. The plate is then displaced, and a second image is produced by illuminating each of the cubes separately, each for the same length of time as in the first experiment.

The result is that on development the resultant impression of the two separate effects is always much more intense than that of the first due to the two conjointly.

The simplest explanation of this curious phenomenon is to suppose that the cube A absorbs the light emitted by the cube B more strongly when it is in a state of fluorescence than when it is screened from the exciting source. At first sight this property of Auorescent bodies appears to be a direct consequence of Kirchhoff's law, all luminous bodies absorbing the radiations which they are capable of emitting. But on looking at the matter more closely we find that this law, which includes so many facts, does not directly apply to the phenomenon discovered by Mr. Burke. This law states, in general, that all bodies, at a given temperalure, have an emissive power and an absorptive power which are equal for each kind of radiation they emit. But we see here a class of bodies which, without having their temperature visibly altered. have their absorptive power changed, in consequence ol the fact that, by a cause ap. parently different from an ele vation of temperature, they

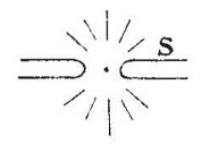

emit, momentarily, and under the action of an external source, radiations which are extinguished at the same time as the excitation itself. By this excitation the molecule is not permanently altered, and it does not become susceptible of vibrating in unison with the light to which it had attained; but if, by an external cause, it is given this vibratory movement, then, and only then, it becomes a resonator for the radiations identicaily the same as that which it emits.

A familiar illustration will give us a more vivid conception of the mechanism of the phenomenon. Let us suppose a sound wave to approach a fixed tuning-fork of another pitch; the wave will pass on unabsorbed. But if we force the tuning-fork in such a way as to make it emit a note identical with that of the wave which approaches it, then it will behave as a resonator and will evidently become absorbent to the passing wave. The tuning-fork is thus capable of absorbing the vibratory energy which reaches it, not merely when the latter corresponds to its natural period of vibration, but also when it possesses a period identical with that of the forced vibration that is momentarily imparted to it.

It is probable, similarly, that the fluorescent molecules are excited momentarily to a forced vibration, and become, for an instant, susceptible of absorbing the vibrations of the same period.

It will be found, perhaps, that the familiar statement of Kirchhoff's law will apply, on comparing the small number of fluorescent molecules in the uranium glass, to any molecules whatsoever which have been raised to a fictitious temperature corresponding to their vibratory state. This extension of the notion of temperature has already been suggested with regard to various luminous phenomena other than that of incandescence, but it had merely led, up to the present, to the heaping up of difficulties without arriving at anything conclusive.

It seems to me far simpler to suppress the notion of temperature altogether in Kirchhoff's law, which is far too general to be limited by a conception that ought to have a precise and definite signification. 